\title{
INFLUENCE OF SEX, AGE AND BODY MASS IN- DEX ON SOME FUNCTIONA INDICES OF PUL- MONARY VENTILATION IN PHYSICALLY ACTIVE CHILDREN
}

\author{
Elena Merdzhanova ${ }^{1}$, Penka Angelova ${ }^{2}$, Nikolay Boyadjiev ${ }^{2}$, Valentina Lalova ${ }^{1}$, \\ Gergana Petrova ${ }^{1}$ \\ 1) Department of Nursing care, Faculty of Public Health, Medical University \\ of Plovdiv, Bulgaria. \\ 2) Department of Physiology, Medicàl Faculty, Medical University of Plovdiv, \\ Bulgaria.
}

\section{SUMMARY:}

Purpose: The purpose of the present study is to examine the impact of age, sex and body mass index (BMI) on some indices of the pulmonary ventilation in healthy children actively practicing sport, between 11 and 14 years of age, living in Plovdiv, Bulgaria.

Materials and methods: A group of 22 healthy volunteers (boys, $n=14$ and girls, $n=8$ ) with high level physical activity underwent a functional test for the evaluation of pulmonary ventilation. In order to assess the influence of age, BMI and sex on some indices of pulmonary ventilation, they were divided into the following groups: in accordance with the age - group 11-12 years old $(n=14)$ and group 13-14 years old $(n=8)$; in accordance with the BMI group $<20 \mathrm{~kg} / \mathrm{m}^{2}(\mathrm{n}=14)$ and BMI group $>20 \mathrm{~kg} / \mathrm{m}^{2}(\mathrm{n}=8)$ and in accordance with the sex - boys group $(n=14)$ and girls group $(n=8)$. The results are presented as $X \pm S D$. The data has been analyzed with Independent Samples Test ( $t$ test) (SPSS v. 13. 0). The difference at $\mathrm{P}<0.05$ was accepted as significant.

Results: We did not find significant differences in most of the indices between the groups by age, body mass index and sex. Although there was higher maximum pulmonary ventilation and higher peak (maximal) expiratory flow in boys compared with the girls.

Conclusion: Despite the good health condition and high level of physical activity, we found out higher maximum pulmonary ventilation and higher peak (maximal) expiratory flow in boys as compared with the girls.

Keywords: spirometry, children, maximum pulmonary ventilation, peak expiratory flow.

\section{INTRODUCTION:}

The functional capacity of the respiratory system is crucial for the growth and health of children and adolescents. The iterrelation between gender, age, body mass index (BMI) and the values of a number of parameters for functional breathing assessment is indisputable. Any change in lifestyle and environmental conditions, such as air pollution in the big cities in the last decades, also has an impact on the respiratory system.

The pulmonary function tests (PFT) are used in the analysis and assessment of the respiratory system. They are used for diagnosing the obstruction of the respiratory tract, assessment of the severity and prognosis of lung diseases, outlining the risk factors (e.g. pre-operational assessment). Spirometry is used for early diagnosis of lung diseases and observation for normal pulmonary growth as well as a decrease in the pulmonary capacity. Unlike the larger part of the biological parameters in medicine, such as plasma concentrations of chemical substances or hormones, the pulmonary function varies depending on age, sex and ethnic belonging [1]. Therefore the results of the tests should be compared with the predicted values for the lower and upper limits of the normal, which are dependent on individual development and lifestyle. There are many published reference values in this respect [2], mostly for spirometric indices studied among Caucasians [3]. For each specific height and sex, a 1-year difference in age may change the expected value by up to $8.5 \%$ [4].

There are different factors that affect lung function in children and adolescents. During childhood, there is an increase in lung volume and gas exchange surfaces. Lung function increases proportionally to the size of the trunk and the chest rather than height. Lifestyle habits since early childhood influence respiratory performance (physical activity and screen time). The age at onset and the time and duration of pubertal development are different between the genders and are influenced by obesity [5].

Resent study on the influence of the training type on male elite athletes' ventilatory function indicated that chronic endurance physical activity leads to adaptive changes in spirometric parameters (VC, FVC, FEV1 and FEV/VC). It did not find significant differences concerning these parameters power athletes and physically inactive individuals [6].

As obesity is a worldwide public health problem, 
its adverse impact on lung function of non-asthmatic children and adolescents is of utmost importance since it may contribute to the increased morbidity of obese subjects. The physicians should be aware of this aspect of obesity and communicate this information to children and their families [7].

There is a range of different factors that predict pulmonary performance, and they must be considered in the evaluation of lung function.

\section{PURPOSE:}

The purpose of the present study is to examine the impact of age, sex and body mass index (BMI) on some indices of the pulmonary ventilation in healthy children actively practicing sport, between 11 and 14 years of age, living in Plovdiv, Bulgaria.

\section{MATERIAL:}

The study covers children aged $11-14(n=22)$, boys $(n=14)$ and girls $(n=8)$, healthy, actively practicing sports, living in Plovdiv. They were subjected a single time voluntarily to a pulmonary function test. A written certificate of excellent health condition of the students and written consent of the parents with regards to the tests have been obtained in advance.

\section{METHODS:}

The measurement of the pulmonary volumes and capacities was carried out with Spirometer (Flowscreen, Erich Jaeger, Germany). The data are entered - date of birth, sex, height $(\mathrm{cm})$ and weight $(\mathrm{kg})$ and the theoretical values of the indexes are automatically calculated [8].

List of measured indices:

- Body mass index (BMI kg/m²)

- Vital capacity (VC) - the maximum air volume which could be exhaled after one maximum breathing in and vice versa.

- Expiratory reserve volume (ERV) - the maximum air volume that can be expired after normal expiration.

- Inspiratory capacity (IC) - the maximum volume of air that can be inspired after a maximum effort.

- Maximal voluntarily ventilation (MVV) - the air volume that can pass through the lungs for 1 minute of rapid and deep breathing.

- Forced vital capacity (FVC) - the air volume exhaled from full inhalation with forced exhalation.

- Forced expiratory volume in 1 second (FEV1) the air volume exhaled with maximal effort for one second after one maximal inhalation.

- Tiffeneau index (FEV1\%VC) - FVC1 towards VC in $\%$.

- Peak (maximum) expiratory flow (PEF) - the maximum air flow per second) in the first $1 / 3$ of forced exhalation.

The results have been presented as a percentage of the individual reference value for each child calculated using software (the reference value complies with age, sex, height and body mass).
All PFT were carried out in the morning, in strict compliance with the rules for their execution.

In order to assess the influence of age, body mass index and sex on some indices of pulmonary ventilation, the participants were divided into the following groups:

In accordance with age - group 11-12 years old $(n=14)$ and group 13-14 years old $(n=8)$;

In accordance with Body mass index - BMI group $<20 \mathrm{~kg} / \mathrm{m}^{2}(\mathrm{n}=14)$ and BMI group $>20 ; \mathrm{kg} / \mathrm{m}^{2} \quad(\mathrm{n}=8)$;

In accordance with gender - group of boys $(n=14)$ and group of girls $(n=8)$.

Statistical processing

The results have been presented as $\mathrm{X} \pm \mathrm{SD}$, we applied The independent samples test ( $t$-test) and used the statistical software SPSS v. 13, accepting as significant the difference at $\mathrm{P}<0.05$.

\section{RESULTS:}

We did not find statistically significant differences in most of the studied indices of pulmonary ventilation in the groups by age, body mass index and sex (Tables 1, 2 and 3 ).

With the study of the peak expiratory flow, we obtained unsatisfactory results (Tables 1, 2 and 3). A possible explanation is that in order to reach an optimal value of the index, a training of the examined individual is necessary for the correct performance of the test and in our case, PFT was carried out only once. For specification of $\mathrm{PEF}$ in healthy children with high physical activity, living in Plovdiv, Bulgaria, it is probably necessary to carry out the functional test several times with a view to the correct execution of the test or additional study with a larger group of students.

While studying the influence of age on some indices of pulmonary ventilation, we found a lower PEF in the group of children aged 13-14 compared with a group of children aged 11-12 (Table 1). In order to clarify the influence of age on PEF in healthy children with high physical activity residing in Plovdiv, it is probably necessary to carry out the functional test several times with a view to its correct execution or additional study with a larger group of students.

While studying the influence of BMI on external breathing, we did not find significant differences in the studied indexes (Table 2). The result is expected as all tested children have an optimal BMI and high physical activity.

While studying the influence of gender for some indexes of external breathing, we found a higher maximal pulmonary ventilation and higher peak (maximal) expiratory flow in boys when compared with girls (Table 3). For specification of the influence of sex on PEF and MVV in healthy children with high physical activity residing in Plovdiv, it is probably necessary to carry out the functional test several times with a view to the correct execution of the test or additional study with a larger group of students. 
Table 1. Results of PFT for both age groups as $\%$ of the individual reference value for each child, calculated using the software.

\begin{tabular}{|c|c|c|c|c|c|}
\hline \multirow{2}{*}{ Indicator } & \multicolumn{2}{|c|}{ 11-12 years old $(n=14)$} & \multicolumn{2}{|c|}{ 13-14 years old $(n=8)$} & \multirow{2}{*}{$\mathbf{P}$} \\
\hline & mean & SD & mean & SD & \\
\hline BMI & 18.26 & 2,64 & 19,01 & 1,88 & $>0.05$ \\
\hline $\mathrm{VC}$ & 120.96 & 48.35 & 101.65 & 31.63 & $>0.05$ \\
\hline ERV & 144.67 & 88.65 & 153.35 & 117.71 & $>0.05$ \\
\hline IC & 103.68 & 33.12 & 89.66 & 65.97 & $>0.05$ \\
\hline MVV & 79.41 & 24.29 & 70.20 & 32.75 & $>0.05$ \\
\hline FVC & 125.72 & 91.03 & 93.55 & 47.53 & $>0.05$ \\
\hline FEV $1 \mathrm{sec}$ & 81.32 & 21.58 & 81.06 & 33.71 & $>0.05$ \\
\hline FEV1\%VC & 63.37 & 29.88 & 75.46 & 22.60 & $>0.05$ \\
\hline PEF & 45.66 & 20.66 & 45.10 & 24,04 & $P=0.058$ \\
\hline
\end{tabular}

Table 2. Results of PFT for both groups depending on BMI as $\%$ of the individual reference value calculated for each child.

\begin{tabular}{|c|c|c|c|c|c|}
\hline \multirow{2}{*}{ Indicator } & \multicolumn{2}{|c|}{ BMI $<20 \mathrm{~kg} / \mathrm{m} 2(\mathrm{n}=14)$} & \multicolumn{2}{|c|}{ BMI >20 kg/m2 (n=8) } & \multirow{2}{*}{$\mathbf{P}$} \\
\hline & mean & SD & mean & SD & \\
\hline $\mathrm{VC}$ & 111.79 & 49.62 & 118.53 & 27.73 & $>0.05$ \\
\hline ERV & 160.37 & 90.31 & 132.78 & 107.30 & $>0.05$ \\
\hline IC & 86.39 & 40.99 & 127.06 & 31.48 & $P=0.075$ \\
\hline MVV & 81.55 & 28.32 & 64.30 & 22.19 & $>0.05$ \\
\hline FVC & 105.81 & 86.36 & 131.60 & 59.45 & $>0.05$ \\
\hline FEV $1 \mathrm{sec}$ & 77.28 & 29.88 & 87.37 & 21.53 & $>0.05$ \\
\hline FEV1\%VC & 67.33 & 28.31 & 70.97 & 26.42 & $>0.05$ \\
\hline PEF & 43.69 & 23.58 & 48.67 & 16.91 & $>0.05$ \\
\hline
\end{tabular}

Table 3. Results of PFT for both groups depending on sex as $\%$ of the individual reference value for each child, calculated using the software.

\begin{tabular}{|l|c|c|c|c|c|}
\hline \multirow{2}{*}{ Indicator } & \multicolumn{2}{|c|}{ Boys group (n=14) } & \multicolumn{2}{c|}{ Girls group (n=8) } & \multirow{2}{*}{ P } \\
\cline { 2 - 5 } & mean & SD & mean & SD & \multirow{2}{*}{$>0.05$} \\
\hline BMI & 18,07 & 2,42 & 19,51 & 2,05 & $>0.05$ \\
\hline VC & 117.91 & 48.27 & 105.43 & 31.43 & $>0.05$ \\
\hline ERV & 144.67 & 88.65 & 153.35 & 117.71 & $>0.05$ \\
\hline IC & 103.68 & 33.12 & 89.68 & 65.97 & 14.26 \\
\hline MVV & 85.55 & 26.92 & 55.74 & 31.09 & $>0.05$ \\
\hline FVC & 128.03 & 90.13 & 83.99 & 20.44 & $>0.05$ \\
\hline FEV 1 sec & 89.03 & 28,12 & 68.91 & 22.55 & $>0.05$ \\
\hline FEV1\%VC & 65.33 & 29.80 & 74.11 & 11,26 & $\mathbf{P}=\mathbf{0 . 0 4 7}$ \\
\hline PEF & 50.45 & 23.41 & 34.77 & & \\
\hline
\end{tabular}




\section{DISCUSSION:}

The positive influence of regular sports activities on some indexes of internal breathing is proven [9]. Aerobic fitness is positively associated with lung volumes. Improving fitness during childhood and adolescence is associated with greater adult lung volumes but not with airway calibre [10].

A survey studying the influence of BMI on some indexes of internal breading finds out that overweight children have a lower functional capacity, but the cause of such malfunction is unclear [11]. Despite the positive correlation between the increase in BMI and pulmonary ventilation up to the age of 5 , in later measurements, whenever there is an increase in BMI in the category of obesity, a downturn in the pulmonary function is observed. These data show a positive contribution of the increase in growth during the early life for the pulmonary function, but if the increase in the weight or the beginning of obesity occurs after the age of 5, an unfavorable impact on the pulmonary function is also observed in adulthood [12]. The results of this study also confirm that BMI, along with sex and age, also influences the indexes of external breathing.

We found a significant difference between boys and girls in terms of the indexes peak expiratory debit and maximum pulmonary ventilation, the boys having higher average values compared with the girls. The reason for this is unclear should also consider the influence of other factors besides sex, age, and BMI.

The changes in the pulmonary functions in children exposed to tobacco smoke, the so called "passive smokers", and children protected against tobacco smoke have been studied, and the obtained results show a difference in the mean values of the peak expiratory debit between the two groups of children [13].

Cardiorespiratory ûtness, or an individual's maximal ability to perform work in a standardized exercise test, is a well-accepted predictor of heart disease and mortality [14] and is considered to be an important element of cardiovascular health [15]. Physical activity and cardiorespiratory ûtness are also associated with peak lung function. Several studies have suggested that increased physical activity among children is associated with higher lung function $[16,17,18]$.

The iterrelation between gender, age, body mass index (BMI), and the values of many parameters for functional assessment of breathing is important not just for diagnosis but also for determining the functional capacity of the respiratory system.

\section{CONCLUSION:}

Despite the good health condition and high level of physical activity, we found out higher maximum pulmonary ventilation and higher peak (maximal) expiratory flow in boys as compared with the girls. Further investigations are required to discover details in pulmonary ventilation in children with high levels of physical activity.

\section{ACKNOWLEDGEMENTS}

This scientific study has been conducted under the project NO-12/2019 of the Medical University of Plovdiv on the topic: Physical development and health behavior of adolescents (11-14 years old) from different ethnic groups in the Municipality of Plovdiv

The scientific work has been presented to The Scientific Ethics Committee on June 28, 2019, which gave its positive opinion with an order of The Rector of Medical University - Plovdiv No. P-1742/28. 06. 2019.

\section{REFERENCES:}

1. Rosenthal M, Bain S H, Cramer D, Helms P, Denison D, Bush A, et al. Lung function in white children aged 4-19 years: I - Spirometry. Thorax. 1993; 48: 794-802

2. Global Lung Function Initiative. Lung Function in Growth and Aging. www.lungfunction.org Date last updated: September 5, 2012. Date last accessed: March 24:2012.

3. Polgar G and Promadhat V. Pulmonary Function Testing in Children: Techniques and Standards. Philadelphia, Saunders, 1971.

4. Wang X, Dockery D, Wypij D, Fay $\mathrm{M}$ and Ferris B. Pulmonary function between 6 and 18 years of age. Pediatr Pulmonol. 1993 Feb; 15 (2): 75-88.

5. Ferreira M, Marson F A, Wolf V L, Ribeiro J and Mendes R. Lung function in obese children and adolescents without respiratory disease: a systematic review. BMC Pulm Med. 2020 October 28;20(1):281. [PubMed]

6. Durmic T, Popovic B, Svenda M, Djelic M, Zugic V, Gavrilovic T et al. The training type influence on male elite athletes' ventilatory function. BMJ Open Sport Exerc Med. 2017; 3:e000240.

7. Fretzayas A, Moustaki M, Loukou I, Douros K. Is obesity related to the lung function of non-asthmatic children? World J Clin Pediatr. 2018 May 8;7(2): 67-74. [PubMed]

8. Seminar Manual of Human Physiology A practical course for medical students. Edited by Professor Nikolay Boyadjiev MD, PhD. Published by Aqua Graphics, Plovdiv, 2018.

9. National Institutes of Health (NIH). August 8, 2001. [Internet]
10. Hancox RJ, Rasmussen F. Does physical fitness enhance lung function in children and young adults? Eur Respir J. 2018 Jan 31;51(2):1701374. [PubMed]

11. Quanjer P, Hall G, Stanojevic S, Cloe T, Stocks J et al. Age- and heightbased prediction bias in spirometry reference equations. Eur Respir J. 2012; 40: 190-197.

12. Kubiak-Janczaruk E. Spirometric evaluation of the respiratory system in adolescent swimmers. Ann Acad Med Stetin. 2005;51(2):105-13.

13. Schivinski CIS, de Assumpcao MS, de Figueiredo FCXS, Wamosy RMG, Ferreira LG, Ribeiro JD. Impulse oscillometry, spirometry, and passive smoking in healthy children and adolescents. Rev Port Pneumol (2006). 2017 Nov-Dec;23(6):311-316. [PubMed] 
14. Kodama S, Saito K, Tanaka S, Maki M, Yachi Y, Asumi M et al. Cardiorespiratory fitness as a quantitative predictor of all-cause mortality and cardiovascular events in healthy men and women: a meta-analysis. JAMA. 2009; 301:2024-2035.

15. Lloyd-Jones DM, Hong Y, Labarthe D, Mozaffarian D, Appel LJ, Van Horn L et al.; American Heart Association Strategic Planning Task Force and Statistics Committee. De- fining and setting national goals for cardiovascular health promotion and disease reduction: the American Heart Association's strategic Impact Goal through 2020 and beyond. Circulation. 2010; 121:586-613.

16. Berntsen S, Wisløff T, Nafstad P, Nystad W. Lung function increases with increasing level of physical activity in school children. Pediatr Exerc Sci. 2008; 20:402-410.

17. Menezes AM, Wehrmeister FC,
Muniz LC, Perez-Padilla R, Noal RB, Silva $M$ et al. Physical activity and lung function in adolescents: the 1993 Pelotas (Brazil) birth cohort study. $J$ Adolesc Health. 2012; 51: S27-S31.

18. Reyfman PA, Washko GR, Dransfield MT, Spira A, Han MK, Kalhan R. Defining Impaired Respiratory Health. A Paradigm Shift for Pulmonary Medicine. Am J Respir Crit Care Med. 2018 Aug 15;198(4):440446. [PubMed]

Please cite this article as: Merdzhanova E, Angelova P, Boyadjiev N, Lalova V, Petrova G. Influence of Sex, Age and Body Mass Index on Some Functiona Indices of Pulmonary Ventilation in Physically Active Children. J of IMAB. 2021 Jul-Sep;27(3):3919-3923. DOI: https://doi.org/10.5272/jimab.2021273.3919

Received: 25/05/2021; Published online: 03/09/2021

Address for correspondence:

Penka Angelova, MD, PhD

Department of Physioligy, Medical Faculty, Medical University of Plovdiv 15 a, Vasil Aprilov, blvd. Plovdiv - 4002

E-mail: angelovapepa@abv.bg, 